\title{
Innovation Strategy of Low Carbon Technology in China: Technology for Market
}

\author{
Xiangsheng Dou, Meijuan Liu, and Hongfei Wang
}

\begin{abstract}
The basis and key of low carbon economy development is low carbon technological innovation. At this stage, China must fully implement the technological innovation strategy of technology-for-market. Only to fully grasp the core or key low carbon technologies and have fully the strong self-innovation capabilities of low carbon technologies, can China take the initiative in the game of global low carbon economy and is not dominated by other countries. The key to the implementation of technology-for-market strategy is to achieve the independent technological innovation and the accumulation of technological capabilities. This requires to protect the intellectual property rights.
\end{abstract}

Index Terms-Low carbon technologies, independent technological innovation strategy, technology for market, accumulation of technical capabilities.

\section{INTRODUCTION}

The basis and key of low carbon economy development is low carbon technological innovation. If there is no low carbon technological innovation, then there is no low carbon economy development. However, in the specific pattern and path of low carbon technological innovation, there are multiple choices. From the innovative strategies and approaches to view, there are two distinctly different patterns of innovation, that is, the market-for-technology and the technology-for-market. The market-for-technology is mainly through the introduction of foreign direct investment to indirectly introduce foreign advanced technology and management experience, and by the way of imitating and learning to promote technological level and innovation capabilities at home, and eventually to realize independent innovation [1], [2]. Furthermore, the technology-for-market is mainly through independent research and development and independent innovation to enhance domestic technological level, technological capabilities and comprehensive competitive power, and through independent intellectual property rights and self-brands to occupy or dominate international markets [3], [4]. Obviously, the path of these two patterns of technological innovation is different.

Then, what pattern should China's low carbon technological innovation exactly take? It has been one of the most important issues what theoretical and practical circles concern in recent years. From the practice of technical innovation in China since the reform and opening up to view,

Manuscript received November 9, 2012; revised January 8, 2013. This work was supported by the National Social Science Foundation of China under Grant 10XJY004.

Xiangsheng Dou, Meijuan Liu, and Hongfei Wang are with the Center for International Economic Research, School of Public Administration, Southwest Jiaotong University, P. R. China (e-mail: douxiangsheng@ tsinghua.org.cn, liumeijuanlily@163.com, wanghongfei1028@126.com). because China is a developing country and its technical level and innovation capabilities are low, so in a long time China has been taking the road of combination of the introduction and the self-innovation of technologies. In the specific introduction way of technologies, especially in the early period of the reform and opening up, China has been mainly implementing the introduction way of technologies of the market-for-technology. It has been proved that, the introduction way of technologies of market-for-technology has indeed played a role in socio-economic and technological development in China. Especially at the early stage of the reform and opening up, because the level of economic and technological development in China is extremely backward, so if China is not through the way of market-for-technology to obtain foreign advanced technology and management experience, then China's socio-economy in the short term is difficult to obtain a leap development [5].

However, because the technology belongs to intellectual property rights, so its inherent property determines that the introduced way of technologies of market-for-technology can only exchange matured technologies, and is not only difficult to exchange for the core or critical technologies, but also in some industries still produces a certain degree of heavy reliance on foreign technologies and has always been difficult to form their own independent technology innovation capabilities [6]. This is painful lessons what the past technical innovation pattern of market-for-technology brought to China. For this reason, low carbon technology innovation of China at this stage can no longer follow the past road of the market-for-technology, and must completely change the philosophy and strategy of technological innovation, and fully implement new technological innovation pattern of taking the technology-for-market as a main tone.

The remainders of paper are organized as follows. Part II discusses "why must China take the innovation strategy of technology-for-market". In part III, we shall investigate the issue of "how to realize the innovation strategy of technology-for-market". Part IV analyses the topic of "the accumulation of technologic capabilities and the innovation strategic transformation". Final part is conclusion.

\section{Why Must CHINA TAKE THE INNOVATION STRATEGY OF TECHNOLOGY-FOR-MARKET}

The reason why the low carbon technology innovation of China must take the innovation pattern of the technology-for-market is that, low carbon economy is a new economy of completely subverting the traditional economy, and it represents the direction and trend of future socio-economic development. In the context of globalization, 
it will be a great global economic game, and only in this global game to occupy a favorable position, can China win more space and more opportunities for development, but the focus of global low carbon game is the capabilities of independent innovation taking low carbon technologies as the core. Therefore, only to fully grasp the core or key low carbon technologies and have fully the strong self-innovation capability of low carbon technologies, can China take the initiative in the game of global low carbon economy and is not dominated by others.

At present, some developed countries taking the United States, the Japan and the European Union as the representative as well as the Russia, the India, the Brazil and other developing countries, are actively promoting low carbon technological innovation. In fact, almost all countries, particularly developed countries, have token low carbon technological innovation as the focus of national innovation strategy and take a series of measures to actively promote, trying on low carbon technological innovation to achieve a significant breakthrough and occupy the commanding heights of low carbon technological innovation in the near future, in order to occupy and dominate the global low carbon technological and industrial markets and to obtain greater benefits in the game of global low carbon economy. Therefore, China must fully learn the beneficial experience of foreign low carbon technological innovation and comprehensively promote independent low carbon technology innovation, and strive on the new round of global economic and technological competition to catch up or surpass developed countries, so as to fully get rid of the passive situation of lagging behind others.

From the real conditions of low carbon technological innovation to view, through socio-economic development for decades since the reform and opening up, at this stage the material and technical equipment in China has reached a higher level, and the capacity of research and development is continually enhancing, and the condition of technological innovation is improving day by day. Therefore, the gap of overall technology level between China and developed countries is shrinking, and the level of technologies in a few fields has caught up or even surpassed developed countries. This indicates that China has already strong independent innovation capabilities. Especially in the field of low carbon technologies, because low carbon economy and its related industries are new things, and low carbon technologies and its applications in the whole world are still at the early stages of research and development, so in this field of technologies the gap between China and developed countries is not obvious.

In the individual field of low carbon technologies such as the solar power panels, wind turbines, hydroelectric equipment and facilities and the others, China is actually already at or approaching the forefront of the world's low carbon technologies, and has fully the capabilities of independent innovation. In the field of renewable and new energy technologies such as new energy vehicles, coal liquefaction, biomass energy, nuclear power and the others, China has also certain capabilities of independent innovation. This creates the foundation and condition for future fierce competition in the field of low carbon technologies between China and other countries in the world. As long as the policy and measures are appropriate, in the near future China is fully capable of occupying the commanding heights of global low carbon technologies, and dominates the development of global low carbon technology markets and low carbon industries [7].

Of course, although China has the potentials and conditions of independent low carbon technological innovation, yet this does not mean that China has already the international competitiveness of low carbon technology markets and industries, for from possessing China's own low carbon technologies to exporting low carbon technologies and then to occupying the international markets of low carbon technologies has still longer road to go, so this will pose a formidable challenge against China. According to the Michel Porter's point of view, a country's competitive advantage shows a comprehensive ability that surpasses her competitors and gains the wealth in the global markets, but the formation of this ability depends on whether the leading industries of a country has a competitive advantage or not. Obviously, on the whole the low carbon technologies and related industries in China at this stage have not still international competitive advantage, and to cultivate the competitiveness involves in three levels of the business, the industry and the nation [8]. Undoubtedly, this will be a complicate and arduous work.

\section{HOW TO REALIZE THE INNOVATION STRATEGY OF TECHNOLOGY-FOR-MARKET}

The strategy of technology-for-market is based on independent technology innovation, and the key to the independent technology innovation is to build an effective system and mechanism of national low-carbon technology innovation. The significance of building a national low-carbon technology innovation system and mechanism is that, it can not only reflect the ieterests and demands of the country for the low-carbon technology innovation activities and thus to give full play to the role and strength of the country, but it is also conducive to the integration and optimization of innovative resources of the whole society, so as to achieve network-typed development and positive interaction of low-carbon technological innovation, which can effectively improve the quality and efficiency of the innovation of low-carbon technologies [4].

At present, because China's low-carbon technology innovation system is still at the exploration and development stage, so the most important task at this stage is to establish and perfect the organization and related network system of national innovation including all main innovation bodies such as the government, the universities and research institutions, the enterprises, the related science and technology intermediary organizations and the others. In these innovative organizations and network system, the universities, the science and research institutions and the enterprises lie in a core position, and they are main forces of low-carbon technology innovation, playing a very important role. From the innovative practices of the developed countries to view, the universities, the science and research institutions and the enterprises are always main body of the most important innovation. Especially, the enterprises are the most active in the technological innovation. Because the 
enterprises directly face the markets and understand the technology needs of the markets and thus the willingness and power to innovate is particularly strong, they always make excellent contributions on the development of application technologies and the standardization and commercialization of technologies.

The role of the government is also very important. Especially, in the case that low-carbon technology innovation system and mechanism at this stage is not very mature, the support, funding, coordination and promotion role of the government is more prominent. Furthermore, for some of major fundamental and critical low-carbon technology innovation activities, it is necessary under the organization and promotion of nation that can be effectively achieved. Because the low-carbon technologies are new technologies, and covers almost all areas of people's production and life, so it is necessary to raise the low-carbon technology innovation to the height of national innovation strategy to treat. To this end, the state and local governments must plan and draw up a scientific low-carbon technology innovation strategy and a clear low-carbon technology innovation roadmap, and to build related strategic organizational system and make related laws and regulations, in order from the system to guarantee the low-carbon technology innovation activities. The second is to use the power of nation to support and subsidize the qualified science and research institutions to carry out basic and critical low-carbon technology innovation activities, in order to achieve a major breakthrough in the major fields of low-carbon technologies. The final is to guide, support and encourage the enterprises to conduct low-carbon technological innovation. For the enterprises being active in low-carbon technology innovation activities, the government should give preferential treatment and encourage in terms of credit, investment and tax, in order to full play the role of enterprise in low-carbon technology innovation.

In modern market-oriented technological innovation process, the role of intermediary organizations of science and technology is also very important. Because many links from the research and development of science and technology to the final promotion and application of the technology need to go through, it needs the technology intermediary organizations to provide appropriate services. From the innovative practice of science and technology of all countries in the world to view, more developed countries in science and technology, then the intermediary organizations of its science and technology are often more developed, too. The role of intermediary organizations of science and technology is that, it can not only provide technical trading services for the supply-side and the demand-side of technologies, but also provide the talents, informations, capitals and other aspects of the service for them. All these are beneficial to accelerate the industrialization development of technologies. At present, many scientific and technological achievements in China are difficult to be timely transformed into real productivity. Obviously, it is related to the underdevelopment of intermediary organizations of its science and technology. Therefore, in the innovation of low-carbon technologies, besides that give full play to the role of universities, science and research institutions and enterprises, we also need to make great efforts to cultivate and develop a large number of intermediary organizations of science and technology. Only by doing so, we are able to really build a vibrant and efficient system and mechanism of national low-carbon technology innovation.

Certainly, the construction of the system and mechanism of low carbon technological innovation only provides an essential condition for low carbon technological innovation. For a great developing country such as China, at this stage it is still necessary to increase domestic low carbon industrial investment and enhance domestic demand for low carbon technologies. To increase the investment of domestic low carbon industry not only can greatly promote the innovation of low carbon technologies and accelerate the commercialization application of low carbon technologies, but also can also drive the development and prosperity of domestic low carbon technologies and related markets. Especially at the earlier stage of low carbon economy development, because low carbon industry is a burgeoning industry and its comparative advantage is not obvious, so it is necessary through certain policy measures to promote low carbon industry investment. Only when low carbon industry investment has reached a certain scale, can low carbon industry by the action of market mechanism quickly grow up. Once low carbon industry has grown up, it will strongly drive the development and prosperity of domestic low carbon technologies and low carbon technological markets, so as to create a condition for the export of domestic low carbon technologies and occupying international markets.

Obviously, only by the development of domestic low carbon industrial and technological markets, can China promote the export of low carbon technologies, so as to get the purpose of the technology for market [9]. Only by achieving the goal of the technology for market and occupying a dominant position in global low carbon technological markets, can the international competitiveness of China's low carbon technologies and industries really form.

It must be pointed out that, the pattern of technology-for-market based on independent technological innovation does not deny the role of the international introduction of technologies and the technical cooperation. In the context of globalization, the openness and cooperation has become new features of technological innovation, and thus low carbon technological innovation should take open innovation road, too [3]. Because low carbon technological innovation is related to many key technology areas and related industries, so it not only requires a lot of knowledge accumulation, but also a huge investment. The implementation of open innovation organically integrates national own low carbon technologies with external low carbon technologies, and this not only saves the R\&D costs and accelerates the pace of technological innovation, but also helps to develop new technologies and market space [9]. For some applied or symbiotic low carbon technologies, China can still through the market-for-technology to introduce. Because the introduction of such technologies has not technological lock-in problems, so the indirect introduction of technologies through the market-for-technology helps to save the cost and time of innovation.

In fact, due to the complexity of low carbon technologies and the huge investment of R\&D of low carbon technologies, 
any country can not fully grasp all of low carbon technologies. To implement internationalization research and development of low carbon technologies, and to optimally allocate the technical factors on a global scale, has become an important strategy of technological innovation of developed countries. More importantly, the United Nations Convention on Climate Change and the Tokyo Protocol has made a commitment for developed countries to transfer their low carbon technologies to developing countries, respectively. China should actively use the opportunities of international low carbon technology transfer to improve and strengthen the capability of low carbon technological self-innovation, so as to take the limited technical resources for the research and development of critical or core low carbon technologies [10].

\section{ACCUMUlation OF TECHNOLOGIC CAPABILITIES AND TRANSFORMATION OF INNOVATION STRATEGY}

The independent technical innovation is established on the basis of the accumulation of certain technical capabilities. If there is no the accumulation of certain technical capabilities, then it is impossible to achieve the independent technological innovation. However, a country's technology accumulation involves in many aspects of the problem, among them, the grasp of core technologies and key technologies is the most critical. One country only gains certain technical accumulation and achieves a leading position in the world in the field of the core technologies and key technologies of the leading industries and basic industries of national economy, can it have a strong capacity for innovation and competitive advantage, in order to lay a solid foundation and condition for realizing the strategic transformation from the "market for technology" to the "technology for market".

According to the Porter's view of point [8], the basis of a country's competitive advantage comes from the vitality of the enterprise and the capability of independent innovation, and thus the construction of independent $\mathrm{R} \& \mathrm{D}$ and innovation capacity of enterprise is particularly important. From the practice of technological innovation in the developed countries to view, the enterprise is always the main force of technological innovation. Especially in the innovation of applied technologies, the enterprises play a vital role. Therefore, in the accumulation of technological capabilities it is necessary fully to rely on the power of the enterprises. At present, many enterprises in China are still at the stage of the introduction and imitation and the digestion and absorption of technologies, and many enterprises have not yet achieved technological independence, which basically restrict the implementation of the technology-for-market strategy. Therefore, it is necessary to strengthen the construction of independent research and development and innovation capabilities of the enterprises, and to gradually realize the technology independence of enterprises, in order to create conditions for the ultimate realization of technology exports.

Of course, either the national or the enterprise's accumulation of technical capabilities, both needs certain external conditions to support. The first is the accumulation of human and knowledge resources, and it is a reliable source of technological innovation. If there are no high-quality human and knowledge resources, then the technological innovation will lose its reliable foundation. However, the creation of high-quality human and knowledge resources requires not only a long time and a lot of investment in human capitals, but also a good social, economic, political and legal environment being suitable for their growth. Therefore, it is necessary to speed up the implementation of the strategy of the human resources and the science and technology, as much as possible to increase the investment of education and human capitals. At the same time, it is also necessary to create a good environment for the growth of talents, and through a variety of means to stimulate the vitality and innovative spirit of all of scientific and technological talents, in order in a not very long time to cultivate a large number of high-quality scientific and technological talents for the scientific and technological undertakings of county, which lay a strong resource base of talents and knowledges for China's own technological innovation.

The second is demand factors. Under the conditions of market economy, the target and power of all economic activities is oriented to the markets, and technological innovation is no exception, too. If the market demand for a product is greater, then it will generate the economies of scale, thereby creating a great deal of space for relevant technological innovation. Conversely, if the market demand for certain product is smaller, it will inhibit the innovative power of companies and related organizations. However, for some technological innovations that have enormous potentials in the future, especially for the strategic technology innovation, in the short term it is difficult to form a huge market demand. In this case, on the one hand, it needs the state to give positive support and encouragement on the aspects of capital, taxation and investment. On the other hand, as far as possible at the policy level to actively create the necessary market and technical demands. This is another important basic work what the countries and relevant departments do in the accumulation of technological capabilities and the train of innovative capacities [8].

Because the accumulation of technological capabilities and the train of innovative abilities is a very complex socio-economic system work, so it is still necessary to make a significant change on innovative ideas and mode, too. With the development of economic globalization and global economic integration, the traditional mode of technological innovation has become increasingly unsuited to the needs of the modern technological innovation, and thus open innovation mode must be taken [9]. The essentials of open innovation mode are organically to mix China's own technologies and external technologies together, and this will help to overcome the contradictions that own technical capacities are limited, to accelerate the accumulation of technological capabilities and rapidly enhance the comprehensive innovation abilities. From the innovative practice in developed countries to view, either the nations or the multinational enterprises, all are actively promoting the open innovation mode. Of course, open innovation is still based on the foundation of strong technical capacities that the main bodies of innovation themselves possess, or it is only simple technology introduction and imitation, and cannot 
really form independent innovation capabilities [10].

The core to enhance the accumulation of technological capabilities and implement the technology-for-market strategy is to protect intellectual property rights. Because technology is an important intellectual property rights, and it has invisible and easily copied feature, if not strictly protected, then it will seriously affect the enthusiasm and initiative of the main bodies of innovation that carry out technical innovation, and ultimately affect the accumulation of technical abilities and the implementation of the technology for market strategy. At present, there are still many problems on China's intellectual property protection and management. Especially, many enterprises are not enough emphasis on the management of intellectual property, which fundamentally restricts the accumulation of technical abilities. Therefore, it is necessary to guide and encourage the main bodies of innovation to establish and perfect the system of intellectual property management, and fully to implement the intellectual property strategy [4].

\section{CONCLUSION}

The core and focus of global low carbon game is low carbon technology innovation. Only the nation of taking an advantage over low carbon technology innovation can occupy a favorable position in global low carbon game, thereby leading and dominating global low carbon economy development. Historical experience has told us that, on the new round of low carbon economy game, China must take the road of technical innovation of the technology for market, and cannot go to the past old road of the market for technology. Only by this way, can China make a strategic advantage in future global competition, and thus to lay a solid foundation for comprehensively enhancing the comprehensive international competitive advantage of nation.

The key to the implementation of technology-for-market strategy is to achieve independent technological innovation. Therefore, it is necessary to build an effective national low-carbon technology innovation system and mechanism. At present, the most important task is to establish and improve the network system of national innovation organization covering all the main bodies of innovation including the government, universities and research institutions, enterprises, science and technology intermediary organizations, and others, and fully play the role of various innovative bodies.

The implementation of technology-for-market strategy is based on the accumulation of technological capabilities, especially the accumulation of core and key technology capabilities. However, the accumulation of technological capabilities requires certain external conditions. The first is the accumulation of human and knowledge resources, and it is a reliable source of technological innovation. Followed by the creation of the technology and market demand, only to create a great technology and market demand, can we create a huge space for technological innovation. In addition, it is still necessary to accelerate the transition from the closed innovation to the open innovation mode, too.

The core to enhance the accumulation of technological capabilities and implement the technology-for-market strategy is the protection of intellectual property rights. Only to establish and improve the system of intellectual property protection, can we arouse the enthusiasm and initiative of various innovative main bodies that carry out the technological innovation, so as to accelerate the pace of technological innovation. Therefore, it is essential to overall strengthen intellectual property protection and management.

\section{REFERENCES}

[1] Z. Y. Zhao, "The intent, feasibility and limitations of the market for technology," Academic Monthly, no. 3, pp. 83-88, March 2007.

[2] C. L. Gao, X. Y. Zhou, and L. Y. Wang, "Can the market-for-technology strategy be achieved," World Economy, no. 8, pp. 14-21, August 2007.

[3] C. C. Zhan, "From market for technology to technology for market-analysis and thinking of Qirui development strategy transformation, Shanghai Economic Research, no. 10, pp. 2-55, October 2007.

[4] L. Z. Luo and Y. J. Chen, "Reflect on the new mode of multinational operations of the market for technology in China's auto companies," International Economic and Trade Research, no. 9, pp. 72-76, September 2008.

[5] X. H. Li, "Reflect on the market for technology after accession to the WTO," China's Industrial Economy, no. 4, pp. 21-26, April 2004.

[6] F. H. Zeng and J. Li, "Study of system arrangement of the market for technology," Management World, no. 5, pp. 191-192, May 2000.

[7] Y. Mulugetta and F. Urban, "Deliberating on low carbon development," Energy Policy, vol. 38, pp. 7546-7549, July 2010.

[8] M. E. Porter, Competitive advantage of nations, 1st ed. pp. 31-90, U.K.: Oxford University Press, 2002.

[9] H. Chesbrough, Open Innovation: The New Imperative for Creating and Profiting from Technology, Boston: Harvard Business School Press, MA, pp. 43-62, 2003.

[10] W. L. Heng and X. Liang, "Strategy for promoting low-carbon technology transfer to developing countries: the case of CCS," Energy Policy, vol. 39, pp. 3106-3116, 2011.

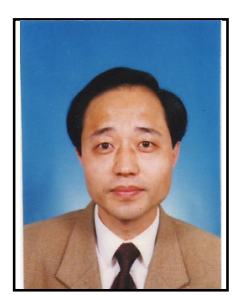

Xiangsheng Dou was born in Dingyuan County of Anhui Province in P. R. China on February 18, 1963. Author's educational background is that, from Sep., 1998 to Jul., 2001, studied as a graduate for a Ph.D degree of economics in the department of economics, Xiamen University, Xiamen City, China. From Sep., 1991 to Jul., 1994, studied as a graduate for a master degree of economics in the department of agricultural economics, Renmin University of China, Beijing City, China. From Sep., 1982 to Jul., 1986, studied as an undergraduate for a bachelor degree of agricultural science in the department of animal science, Anhui University of Science and Technology, Chuzhou City, China. The author's major fields of study are the international economics, mathematic economics, and development economics, etc.

He has been worked in the Southwest Jiaotong University Since April, 2004 as a Professor of Economics, in Chengdu, China. From Jan., 2001 to Jan., 2004, worked in the Post-Doctoral Mobile Stations of Management Science and Engineering in School of Economics and Management of Tsinghua University (a Post-Doctor Researcher). From Sep., 1994 to Aug., 1998, worked in the College of Anhui Provincial Committee of China Communist Party ( a Lecturer ). From Jul., 1986 to Aug., 1991, worked in Agricultural Bureau of Dingyuan County, Anhui province (a Clerk and Assistant Expert). He is currently engaging in the research of low-carbon economy and sustainable development. He has published more than 50 journal and conference papers, 1 research books, and 3 textbooks. He is now directing a project of the National Social Science Foundation of China. Nowadays, he mainly engages in the research and teaching work of international economics, econometrics and development economics.

Prof. Dou is a referee of some journals such as the Renewable and Sustainable Energy Reviews, the Economic Modeling, and so on. 


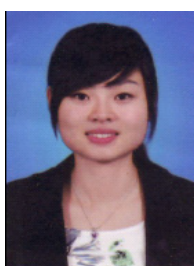

Meijuan Liu was born in Tieling City of Liaoning Province in China on May 28, 1989. Author's educational background is that, from Sep., 2008 to Jul., 2012, studied as an undergraduate for a bachelor degree of economics in the department of economics, Southwest Jiaotong University, Chengdu City, P. R.

China. She has been studied in the Southwest Jiaotong University since Sep., 2012 as a Master Candidate of Theoretical Economics, in Chengdu, China.

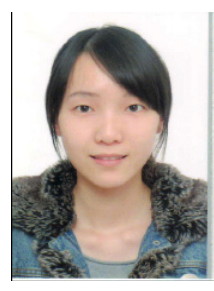

Hongfei Wang was born in Jinhua City of Zhejiang Province in China on Oct. 28, 1990. Author's educational background is that, from Sep., 2008 to Jul., 2012, studied as an undergraduate for a bachelor degree of economics in the department of finance, Sichuan University, Chengdu City, P. R. China. She has been studied in the Southwest Jiaotong University since Sep., 2012 as a Master Candidate of Theoretical Economics, in Chengdu, China. 